\title{
Imaging of the anorectal region
}

\author{
S.M. Hussain*, J. Stoker, H.E. Schütte, J.S. Laméris \\ Department of Radiology, University Hospital Rotterdam (Dijkzigt), Dr Molewaterplein 40,3015 GD Rotterdam, The Netherlands
}

Received 22 December 1995; revised 5 January 1996; accepted 10 January 1996

\begin{abstract}
Imaging of anorectal region has drastically changed during the last decade. Transrectal ultrasound and transrectal MRI can be used for staging the rectal tumours. Endoanal sonography can be applied for the classification of perianal fistulae and identification of anal sphincter defects in patients with faecal incontinence. Due to the limitations of endoanal sonography, endoanal MRI was introduced to assess the pathology related to the anal sphincter complex. Endoanal MRI seems superior to endoanal sonography. This paper describes the new developments of the imaging techniques and presents new insights in anatomy and pathology of the anorectum.
\end{abstract}

Keywords: Anus, radiography; Rectum, abnormalities; Rectum, radiography; Rectum, US; Rectum, MRI; Magnetic resonance (MR), rectum; Ultrasound, utilization

\section{Introduction}

The anorectum is of paramount importance since it is essential to the mechanism of faecal continence. In addition, it is prone to many diseases, such as anorectal tumours and perianal fistulae. Faecal incontinence can be caused by anal sphincter defects [1]. Imaging of the anorectal region, which is crucial for appropriate surgical management, has drastically changed during the last decade [2].

Transrectal ultrasound (TRUS) and transrectal MRI can both be used for staging the rectal tumours $[3,4]$. Endoanal sonography can be used for classification of perianal fistulae and identification of anal sphincter defects in patients with faecal incontinence $[5,6]$. Due to limitations of endoanal sonography, endoanal MRI was introduced to assess the diseases related to the anal sphincter complex [7].

In this paper, new developments in the imaging techniques and the new insights in the anatomy and pathology of the anorectal region will be described.

\section{Anatomy of the anorectum}

The anatomy of the rectum is well established [8]. The anorectum is the most distal part of the colon and is

\footnotetext{
* Corresponding author, Tel.: +31 104634090 ; Fax:+31 104634033.
}

located extraperitoneally. The layers of the rectal wall consist of the mucosa, the submucosa and the muscularis propria. The latter can be subdivided into the inner circular and the outer longitudinal muscle layer. The rectum is surrounded by the perirectal fat and the perirectal fascia (Fig. 1).

The anatomy of the anal canal is more controversial [9]. The inner circular layer of the muscularis propria of the rectum extends into the anal canal and becomes the internal anal sphincter. The outer longitudinal component of the muscularis propria extends as the longitudinal layer of the anal canal. These two layers are surrounded by the external anal sphincter, the puborectalis muscle and the levator ani muscle (Fig. 1). The anatomical concept of the external sphincter, described as a one-, two- or three-part structure [10-12], remains controversial in the literature [9].

\section{Imaging techniques}

\subsection{Transrectal ultrasound and endoanal sonography}

In our department, for sonography of the anorectal region, a Brüel and Kjaer (Naerum, Denmark) ultrasound system is used, with a 5- to $7-\mathrm{MHz}$ rotating transducer. For TRUS, a balloon is inflated with 35-70 $\mathrm{ml}$ of deaerated water, which covers the tranducer. For endoanal sonography, a hard, sonolucent plastic cone 


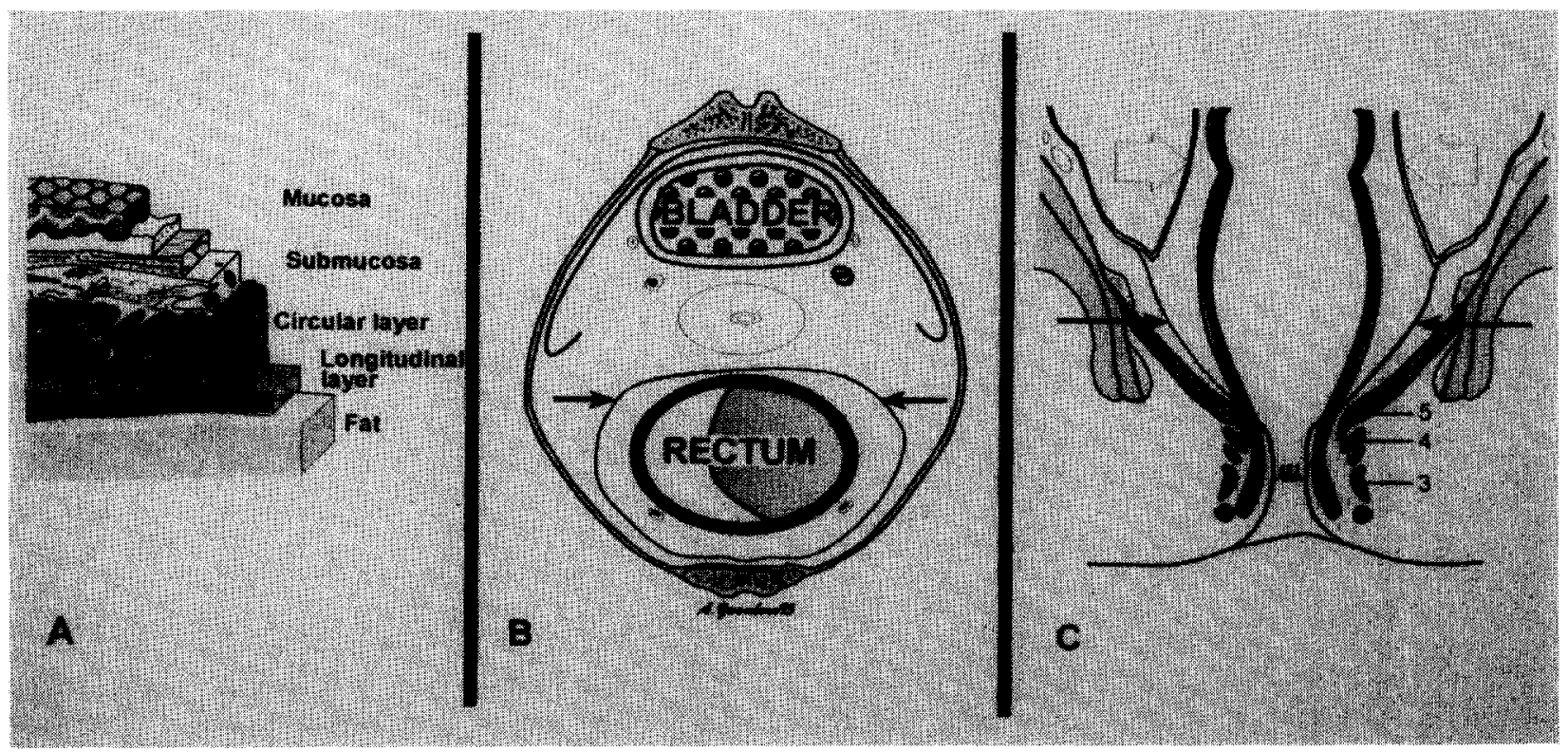

Fig. 1. The anatomy of the anorectum. The layers of the rectal wall are shown (a). The circular (1) and the longitudinal layers (2) form the muscularis propria. Note the perirectal fascia (arrows) in the axial view of the rectum (b). In the coronal view (c), the two layers of the muscularis propria $(1+2)$ extend into the anal canal as the internal anal sphincter and the longitudinal layer. Note the position of the peritoneum (open arrows), the perirectal fascia (arrows), the levator ani muscle (5), the puborectalis muscle (4), and the external anal sphincter (3).

with an external diameter of $17 \mathrm{~mm}$ covers the transducer and is filled with degassed water for acoustic coupling. The probes are slowly retracted and axial $360^{\circ}$ images obtained, respectively through the rectum and the anal canal.

\subsection{Transrectal $M R I$ and endoanal $M R I$}

MR imaging is performed at $0.5 \mathrm{~T}$ (Gyroscan T5-II, Philips Medical Systems, Best, The Netherlands). To reduce the bowel motion, $1 \mathrm{ml}$ of Buscopan $(20 \mathrm{mg} / \mathrm{ml})$ is injected intramuscularly before image aquisition. For transrectal MRI and endoanal MRI, a newly developed rigid coil (Philips Medical Systems) is used.

For axial images a T2-weighted three-dimensional gradient echo sequence (acquisition time, $6.5 \mathrm{~min}$; imaging matrix, $205 \times 256$; two signals acquired; 30/13 (repetition time $\mathrm{ms} / \mathrm{echo}$ time $\mathrm{ms}$ ); flip angle $60^{\circ}$, field of view, $140 \mathrm{~mm}^{2}$; section thickness, $2 \mathrm{~mm}$ ) is placed perpendicular to the long axis of the coil. For the sagittal and the coronal images T2-weighted turbo spin-echo sequences are performed (acquisition time, $5.0 \mathrm{~min}$; imaging matrix, $186 \times 256$; eight signals aquired; $2800 / 120$; turbo factor, 10 ; field of view, $120 \mathrm{~mm}^{2}$; section thickness, $4.0 \mathrm{~mm}$; intersection gap, $0.4 \mathrm{~mm}$ ). The coronal sections were obtained parallel to the long axis of the coil.

\section{Normal imaging findings}

\subsection{Rectum}

The layers of the rectal wall are well visualized with TRUS as well as with transrectal MRI (Fig. 2).

\subsection{Anal canal}

With endoanal MRI, all muscle layers of the anal canal wall, comprising of the internal anal sphincter, the longitudinal layer, the external anal sphincter and the puborectalis muscle, are consistently demonstrated (Fig. 3b) [13]. With endoanal sonography, the internal sphincter is well recognized as a hypoechoic layer while other structures were variably demonstrated (Fig. 3a) [13].

In the coronal plane, the most important finding, unlike the previous concepts [10-12], is that the muscles of the lower and the upper part of the anal canal are different (Fig. 4). The lower part is surrounded by the internal anal sphincter, the longitudinal muscle layer and the external anal sphincter, whereas the upper part is comprised of the internal anal sphincter, the longitudinal muscle layer and the puborectal muscle. The latter muscle slings the anal canal instead of completely surrounding it. The whole sphincter apparatus is embedded 


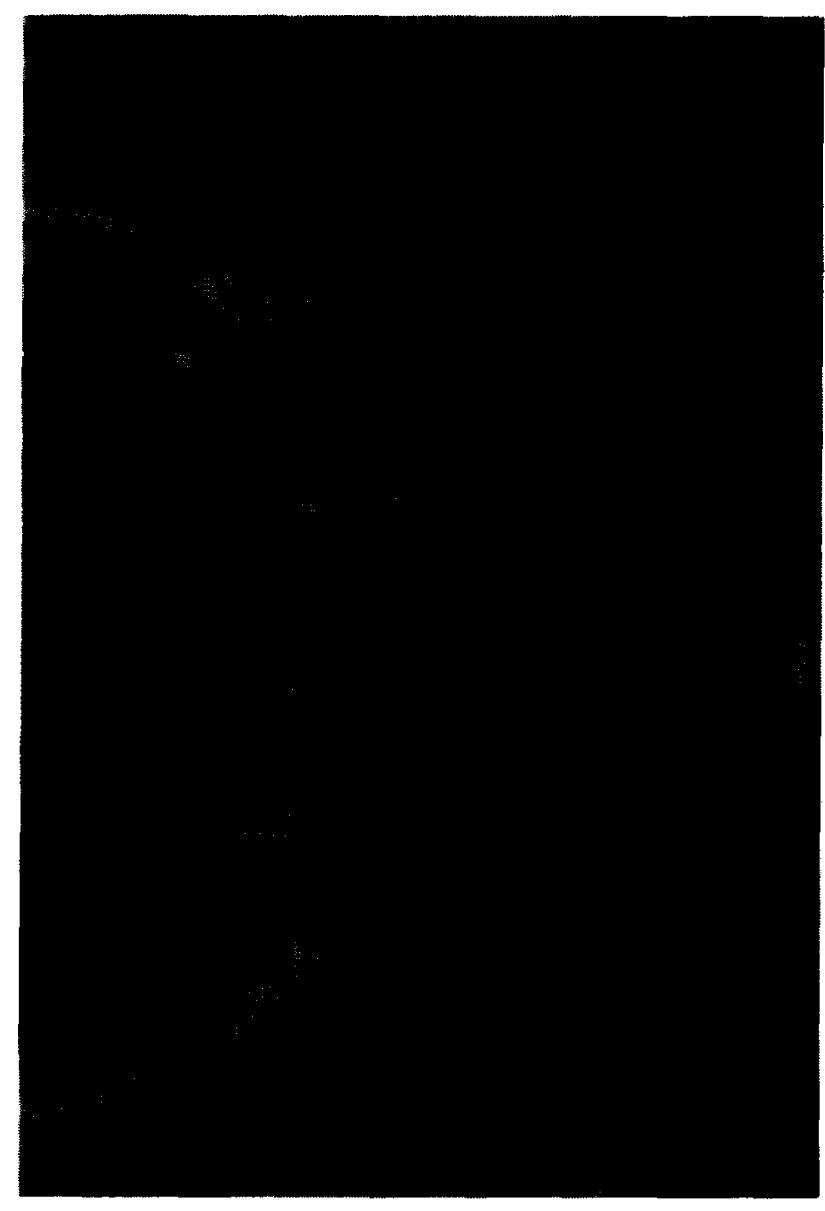

$\mathbf{a}$

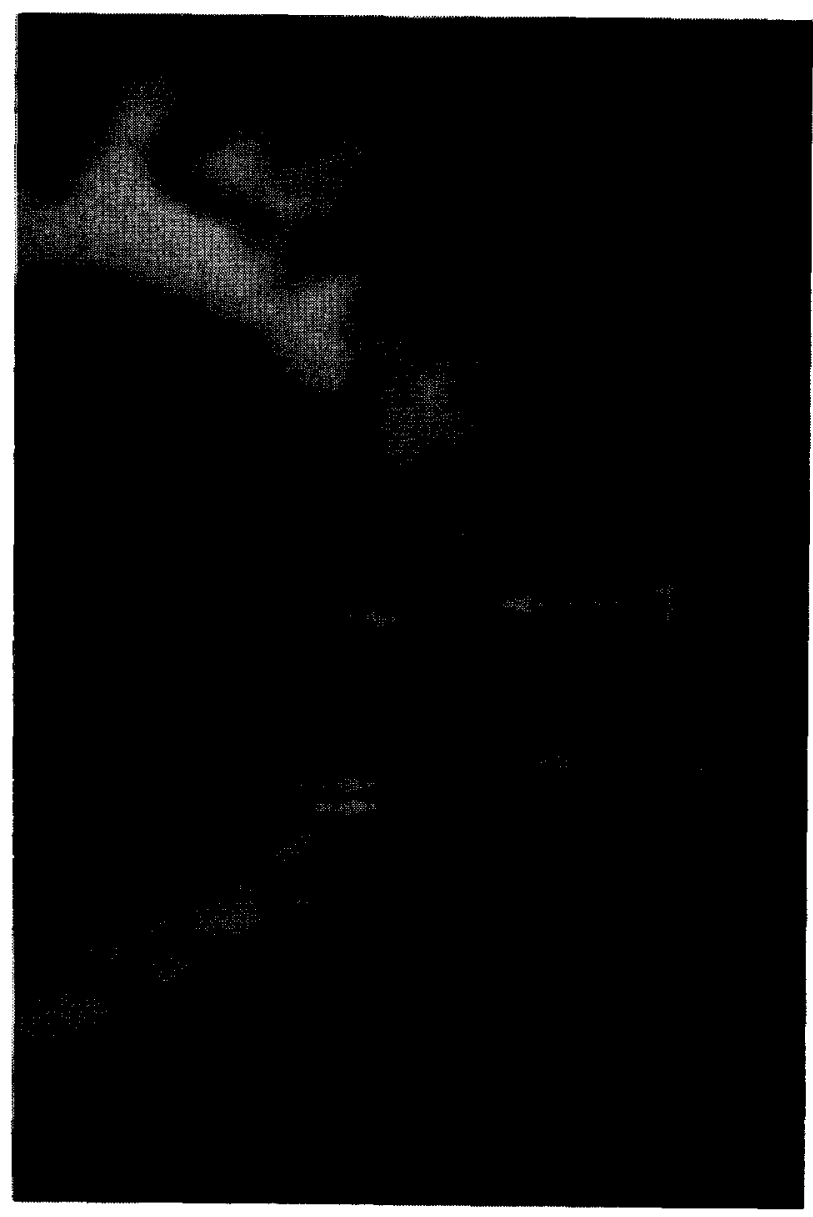

b

Fig. 2. Normal transrectal ultrasound (TRUS) and transrectal MRI. (a) TRUS shows the hypoechoic interface between the water-filled balloon and the mucosa (arrow), the hyperechoic submucosa (double arrows), and two layers of the muscularis propria, the inner (1) and the outer layer (2). Note the fat surrounding the rectum. (b) The same layers can be seen with transrectal MRI.

within the ischioanal space. At its upper end the puborectalis muscle is attached to the funnel-shaped levator ani muscle and the levator ani anchors the sphincter complex to the inner side of the pelvis (Fig. 4). The imaging findings of endoanal MRI correlate well with the cross-sectional anatomy [2].

\subsection{The perianal anatomical spaces}

The fat-containing perianal anatomical spaces are well visible with endoanal MRI (Fig. 4). The visualization of these spaces is important in relation to the inflammatory disease in this area.

\section{Anorectal abnormalities}

\subsection{Faecal incontinence}

Faecal incontinence is a common problem. The prev- alence in the community has been estimated as $2-13$ per 1000. The prevalence increases with age [1].

The common causes of faecal incontinence are the obstetric injury and previous operative procedures, such as lateral internal sphincterotomy, fistula surgery, and hemorrhoidectomy. Less common causes can be aging, rectal prolapse, trauma, irradiation, neurogenic disease (for instance diabetic neuropathy), congenital abnormalities and primary disease such as ulcerative colitis. Childbirth is considered the most common cause of faecal incontinence [1].

The imaging of the anal sphincter is essential to identify the patients with sphincter damage in a population with faecal incontinence. Currently, endosonography is the investigation of choice for identification of the sphincter damage in patients with incontinence [6]. The external sphincter damage, however, can be difficult to appreciate with endoanal sonography [2]. With endoanal MRI, all layers of the anal canal wall are well 


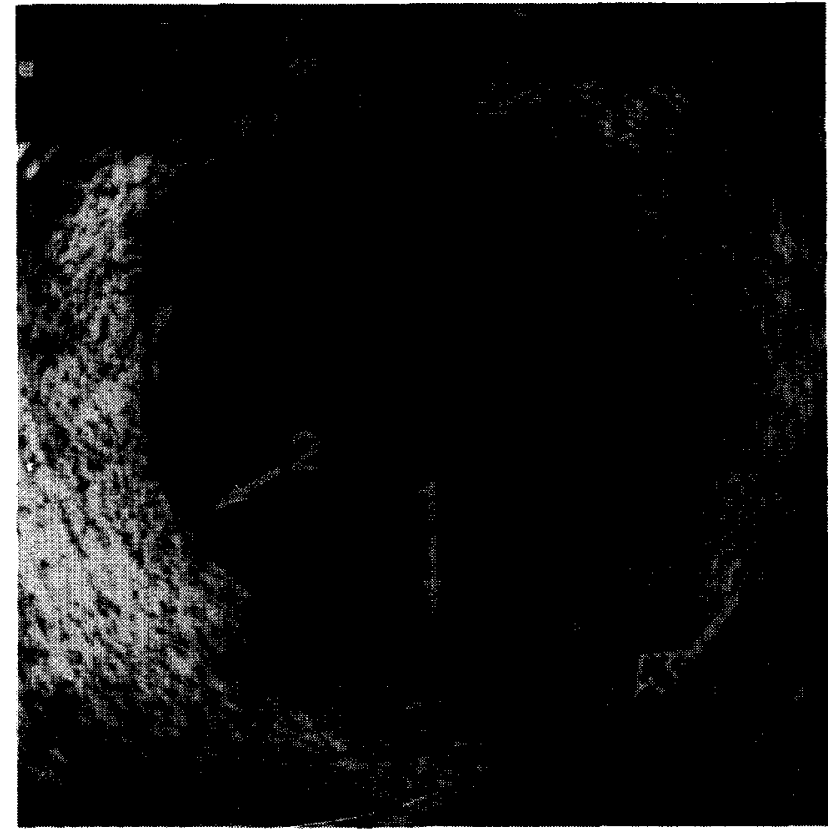

$\mathbf{a}$

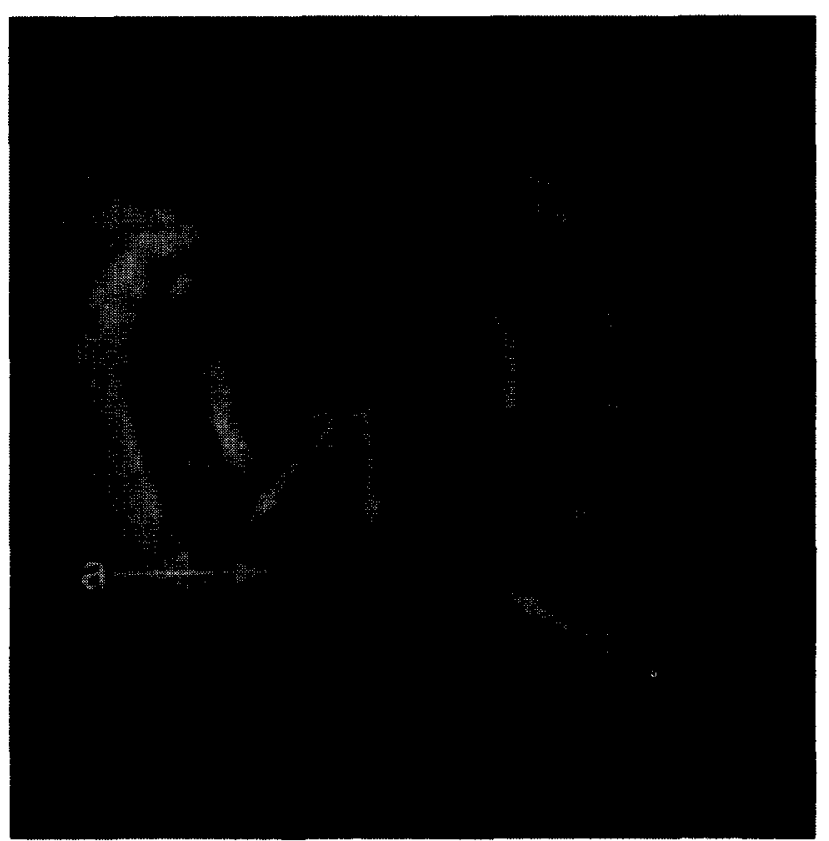

b

Fig. 3. Normal endoanal sonography and MRI. Axial images. The internal anal sphincter (1) is well recognizable with both modalities. Just outside the internal sphincter, another thin hypoechoic layer is visible with sonography (a) which corresponds well with the longitudinal layer (2) on the MR image (b). The hyperechoic band (open arrow) shows no correlation with the external sphincter (3) apparent with endoanal MRI. Intersphincteric space (a).

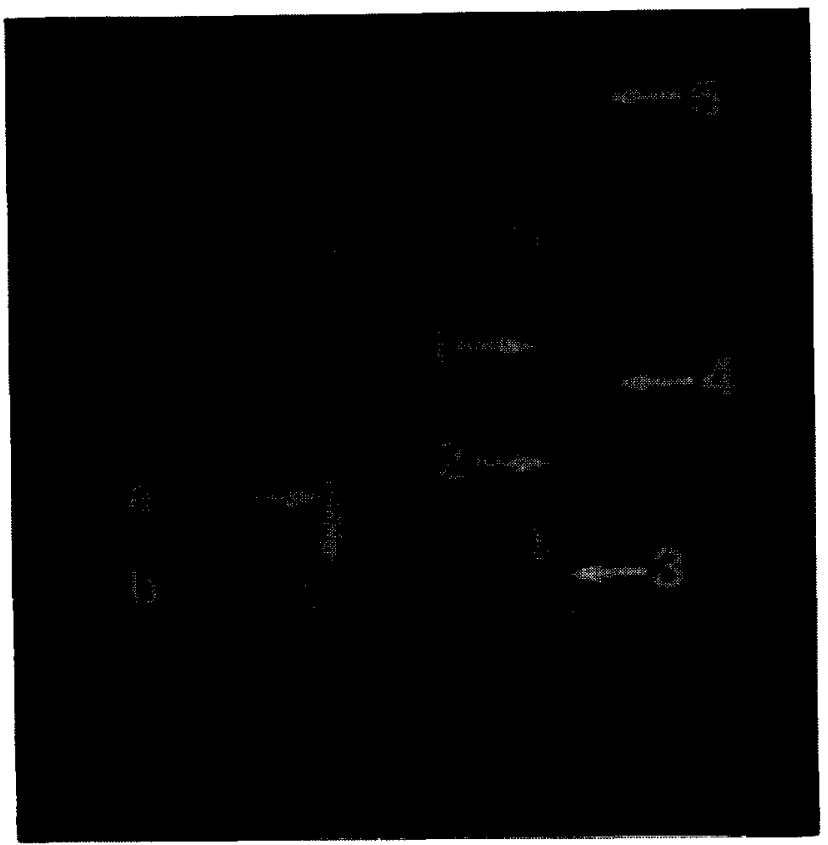

Fig. 4. Normal endoanal MRI. Coronal image. The muscles in the lower and in the upper part of the anal canal are different. Internal anal sphincter (1). Longitudinal layer (2). External anal sphincter (3). Puborectalis (4) and levator ani muscles (5). Intersphincteric (a) and ischioanal spaces (b). visualized; therefore the defects of both the internal and the external anal sphincter are well recognized with this technique (Fig. 5) [14].

\subsection{Fistula-in-ano}

Fistula-in-ano is an abnormal communication between the anal canal and the perianal skin. The perianal abscess is an acute manifestation and the fistula-in-ano a chronic condition of the same disease. The perianal fistulae occur in about 10 per 100000 of the general population [15]. In tertiary referral centres, this disease, however, is a common problem. The treatment of fistula-in-ano is surgery. To diminish the postoperative occurrence of faecal incontinence and to keep the recurrence rate as low as possible, understanding of the exact relationship of the fistula to the perianal anatomical structures and spaces is crucial [16]. In this respect, imaging can play an important role.

Most cases of fistula-in-ano are non-specific, i.e. without an underlying disease, and result from inflammation of anal glands [1]. All non-specific fistulae have their starting-point in the intersphincteric space [1]. Fistula-in-ano can be divided into intersphincteric, transsphincteric, suprasphincteric and extrasphincteric fistulae [16]. Anal fistulae can also be of specific type, such as due to Crohn's disease, tuberculosis or rectovaginal fistula [1]. 


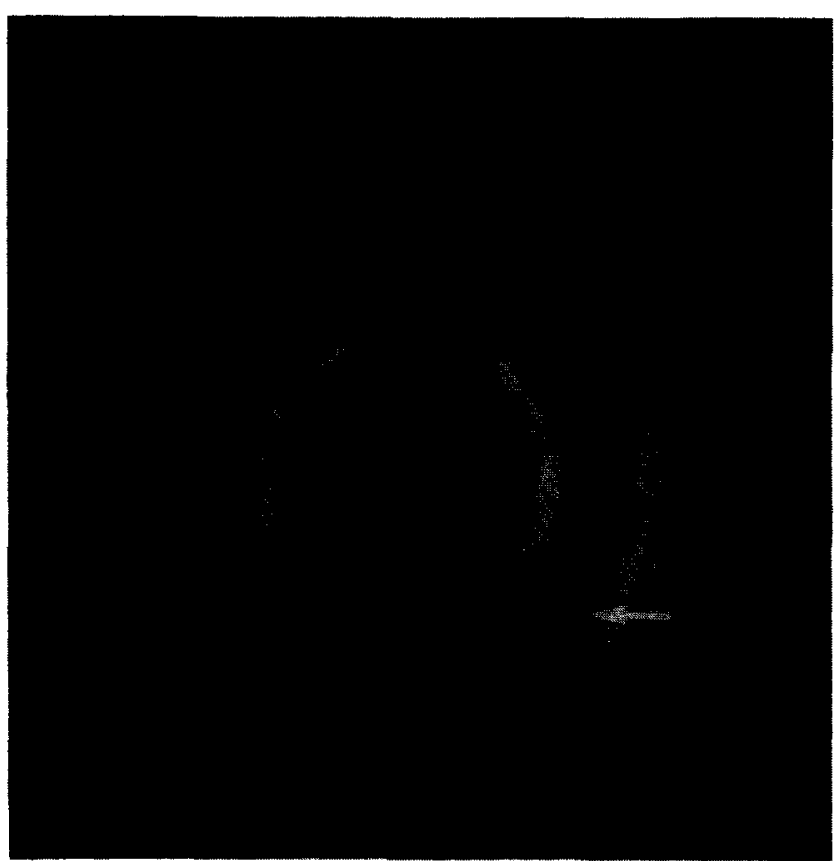

a

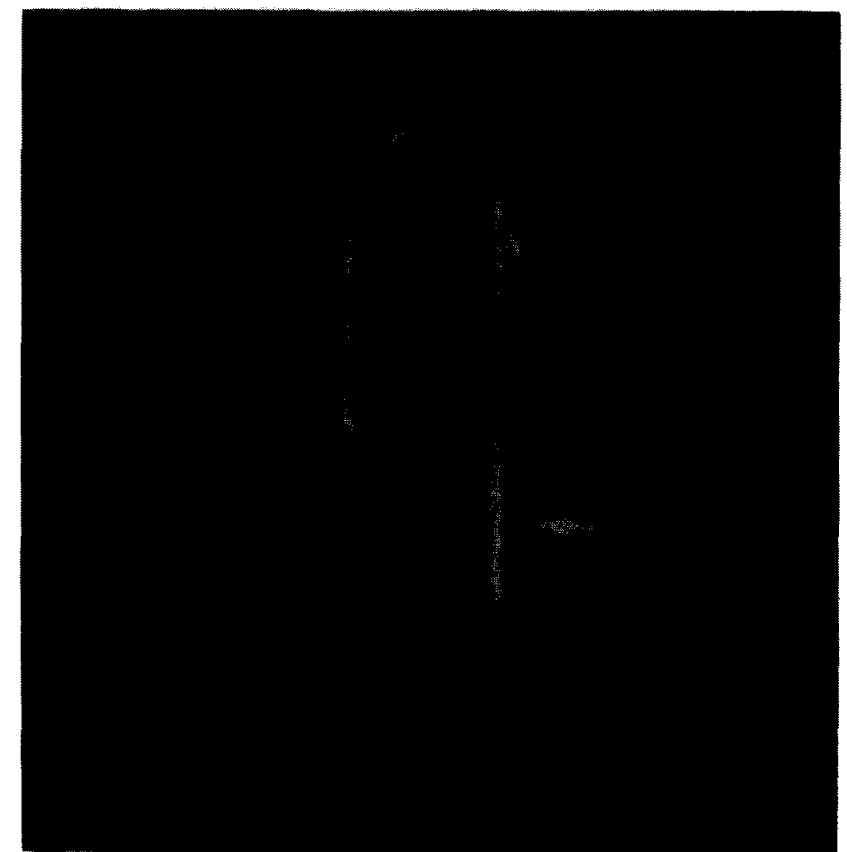

b

Fig. 5. A 36-year-old man who became incontinent after fistulectomy. Axial (a) and coronal (b) endoanal MRI showing the internal and external sphincter defects on the left side of the anal canal (arrow). Note that the muscle layers on the right side are normal in appearance.

With endoanal sonograpy, perianal fistulae can be difficult to recognize [2]. Preoperative classification of fistula-in-ano is not always possible with sonography [17] or surface coil MRI [18]. With endoanal MRI, the fistula-in-ano can be classified more accurately (Fig. 6). The better visualization of the fistula, and the anatomical structure and spaces, is the basis for the improved results with endoanal MRI [17].

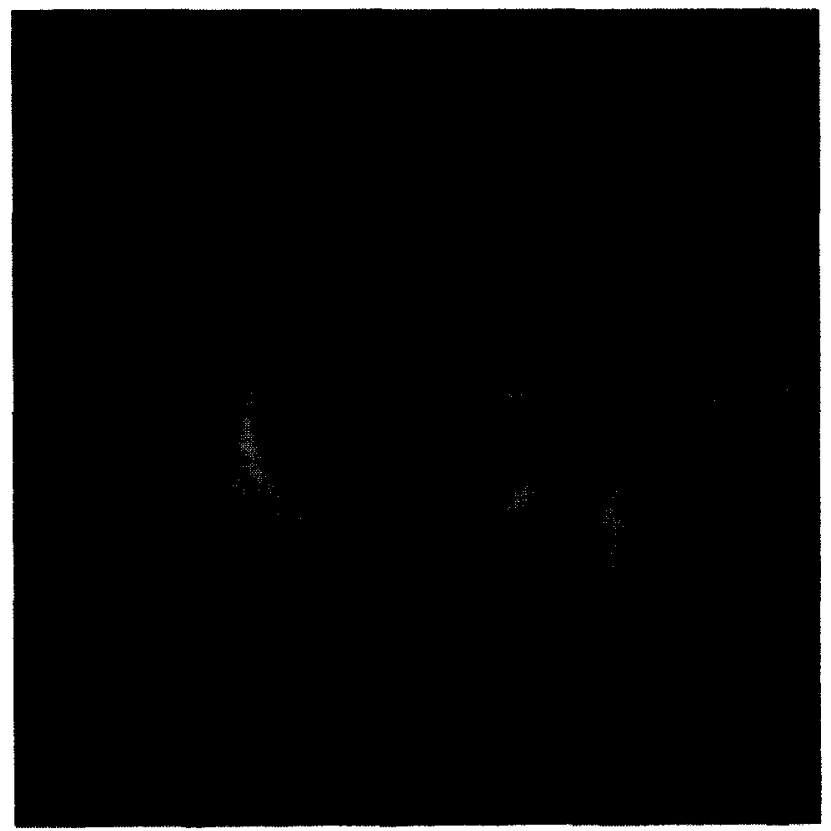

$\mathbf{a}$

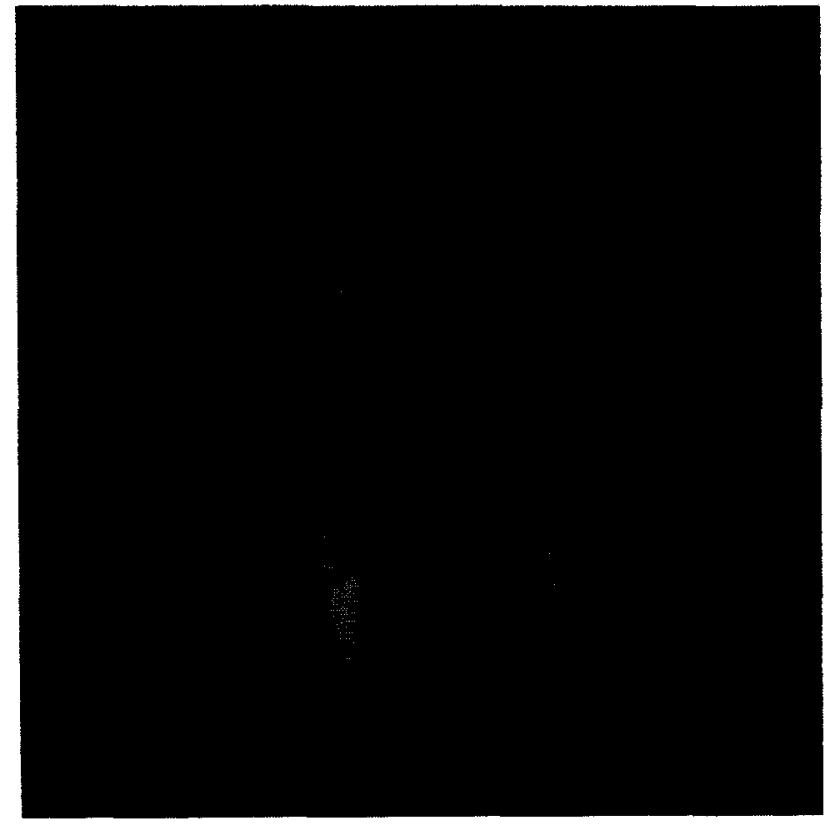

b

Fig. 6. A 28-year-old man with a non-specific, cryptoglandular fistula. Axial (a) and coronal (b) endoanal MRI showing an intersphincteric fistula. The fistula (arrow) is hyperintense and is clearly visible between the internal (1) and the external anal sphincter (3). 


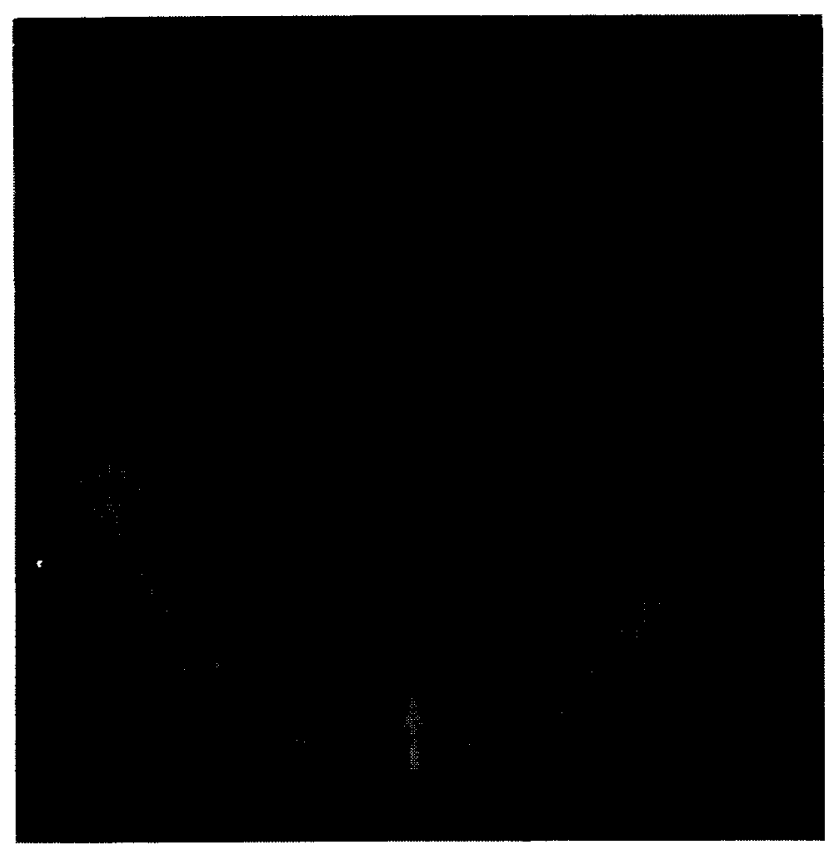

a

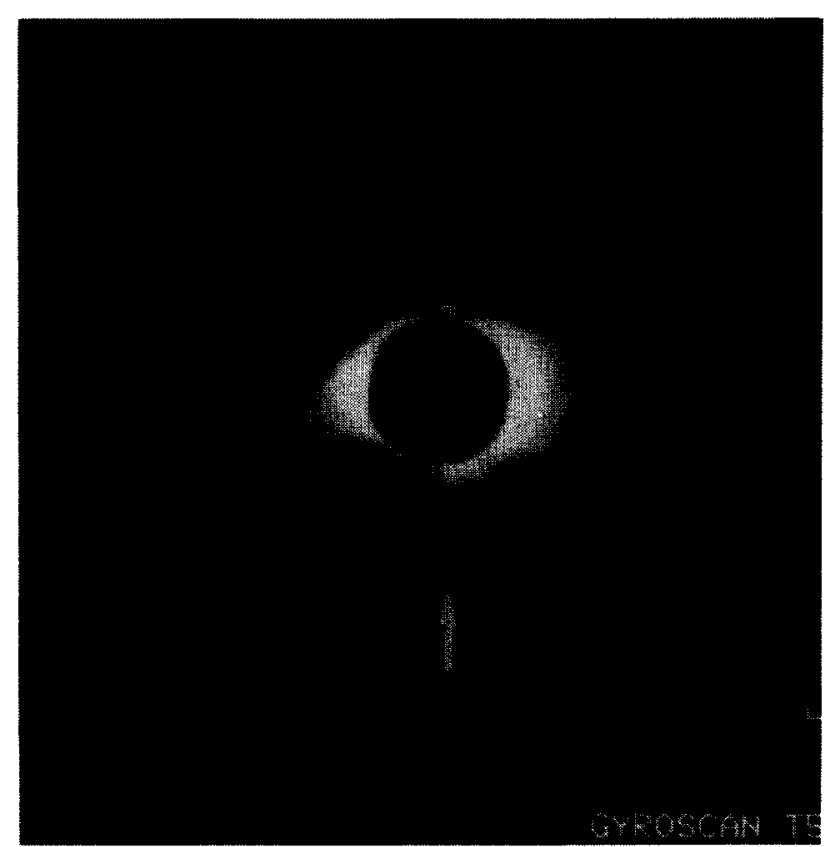

b

Fig. 7. A 56-year-old woman with a rectal carcinoma. Axial TRUS (a) and transrectal MRI (b) showing a tumour (arrow) confined within the muscularis propria (T2 tumour).

\subsection{Rectal tumours}

Colorectal cancer ranks as second commenest to lung cancer in males and second to breast cancer in females. Approximately one half of the cancers are in the rectosigmoid [1].

For TNM-staging of the rectal tumours, the visualization of the layers of the bowel wall is important [3]. Transrectal ultrasound (TRUS) and transrectal MRI are well able to correctly stage the rectal tumours (Fig. 7). Understaging is often due to the errors of interpretation and technical problems [2]. Overstaging is often due to the desmoplastic reaction, i.e. a reactive inflammatory change on the outer border of the tumours [2].

\section{Discussion and conclusions}

The anatomy of the anorectum has been controversial for several reasons. The relationship of the muscles of the pelvic floor and adjacent structures is complex. This region is relatively inaccessible to investigators, including anatomists and clinicians. In addition, the organs responsible for sexual intercourse and defaecation are located in this area, which makes this region guilt-ridden and relatively difficult to investigate in the living subject.

The introduction of endosonography [19] and endo MRI [7] has changed the imaging of this region. With these two imaging modalities, it is now possible to image the anal sphincter complex and the rectal wall in vivo.
Normal endoanal MR anatomy of the anal sphincter complex appears in many aspects to be different than the present-day anatomical views [13]. Separate comparative studies have been carried out in patients with faecal incontinence [14], anal fistulae [17], and rectal tumours [2]. Initial results show that endoanal MRI is superior to endoanal sonography in patients with faecal incontinence and anal fistulae. In patients with rectal tumours, the two modalities seem similar in staging of the tumours.

\section{Acknowledgments}

Thanks are due to Andries Zwamborn and Teun Rijsdijk for preparing the drawings and the photographs.

\section{References}

[1] Gordon PH, Nivatvongs S. Principles and practice of surgery for the colon, rectum, and anus. St. Louis, MO: Quality Medical Publishing, 1992; 407-417.

[2] Hussain SM, Stoker J, Zwamborn AW, Den Hollander JC, Schouten WR, Laméris JS. Imaging of anorectal diseases. Radiology 1995; 197 (P): 500.

[3] Tio TL, Coene PPLO, Van Delden OM, Tytgat GN. Colorectal carcinoma: preoperative TNM classification with endosonography. Radiology 1991; 179: 165-170.

[4] Schnall M, Furth EE, Rosato E, Kressel HY. Rectal tumor stage: correlation of endorectal MR imaging and pathologic findings. Radiology 1994; 190: 709-714. 
[5] Law PJ, Talbot RW, Bartram CI, Northover JMA. Anal endosonography in the evaluation of perianal sepsis and fistula in ano. Br J Surg 1989; 76: 752-755.

[6] Sultan AH, Kamm MA, Hudson CN, Thomas JM, Bartram Cl. Anal-sphincter disruption during vaginal delivery. N Engl J Med 1993; 329: 1905-1916.

[7] Hussain SM, Stoker J, Kuiper JW, Schouten WR, den Hollander JC, Laméris JS. MR imaging of anal sphincter complex with an endoanal coil: normal anatomy and pathology. Radiology 1994; 193 (P): 445.

[8] Grabbe E, Lierse W, Winler R. The perirectal fascia: morphology and use in staging of rectal carcinoma. Radiology 1983; 149: 241-246.

[9] Dalley II AF. The riddle of the sphincters. The morphophysiology of the anorectal mechanism reviewed. Am Surg 1987; 53: 298-306.

[10] Milligan ETC, Morgan CN. Surgical anatomy of the anal canal. Lancet 1934; ii: 1150-1156.

[11] Goligher JC, Leacock AG, Brossy JJ. The surgical anatomy of the anal canal. Br J Surg 1955; 43: 51-61.
[12] Oh C, Kark AE. Anatomy of the external anal sphincter. Br J Surg 1972; 59: 717-723.

[13] Hussain SM, Stoker J, Laméris JS. Anal sphincter complex: endoanal MRI of normal anatomy. Radiology 1995; 197: 671-667.

[14] Hussain SM, Stoker J, Schouten WR, Laméris JS. Highresolution endoanal MRI of the anal sphincter complex: normal anatomy and sphincter defects. Eur Radiol 1995; 5: S314.

[15] Sainio P. Fistula-in-ano in defined population. Incidence and epidemiological aspects. Acta Chir Gynaecol 1984; 73: 219-224.

[16] Parks AG, Gordon PH, Hardcastle JD. A classification of fistula-in-ano. Br J Surg 1976; 63: 1-12.

[17] Hussain SM, Stoker J, Elevelt AJ, Schouten WR, Laméris JS. Fistula-in-ano: endoanal sonography vs. endoanal MRI. Radiology 1995; 197 (P): 379.

[18] Lunniss PJ, Armstrong P, Barker PG, Reznek RH, Phillips RK. Magnetic resonance imaging of anal fistulae. Lancet 1992; 340: 394-396.

[19] Law PJ, Bartram CI. Anal endosonography: technique and normal anatomy. Gastrointest Radiol 1989; 14: 349-353. 